\title{
A EVANGELIZAÇÃO DO NOVO MUNDO: O PLANO DO PE. MANUEL DA NÓBREGA
}

\author{
Rafael Chambouleyron \\ Doutorando em História Social pelo Departamento de História/FFLCH-USP
}

\begin{abstract}
RESUMO: O artigo procura analisar a percepçāo da realidade colonial através dos escritos do Pe. Manuel da Nóbrega; trata-se, a partir dai, de entender a constituição de um projeto ordenador de evangelização e colonização para a América portuguesa.
\end{abstract}

ABSTRACT: This article analyzes the perception of colonial reality based on the writings of Priest Manuel da Nobrega; such an analysis deals with the establishment of an ordaining project of evangelization and colonization for Portuguese America.

PALAVRAS-CHAVE: Companhia de Jesus, Evangelização, Colonização, Manuel da Nóbrega, Projeto Jesuítico.

KEY-WORDS: Society of Jesus, Evangelization, Colonization, Manuel da Nóbrega, Jesuitical Project.

Este texto procura examinar as particularidades do discurso do Pe. Manuel da Nóbrega (1517-1570) a respeito da colonização da América portuguesa. $O$ seu projeto de evangelização organizou-se em torno de um plano ordenador do conjunto da sociedade colonial, ultrapassando, portanto, o mero âmbito da catequese dos indígenas - principal missão da Companhia de Jesus.

As suas reflexões, realizadas a partir dạ realidade colonial, inserem-se, entāo, em um movimento mais amplo, em um processo que assistiu à formação dos Estados modernos e à constituiçāo de um sistema colonial - que, entre outros fatores, procu- rou organizar a vida que se iniciava nos territorios descobertos.

Debruçar-se sobre o apostolado da Companhia de Jesus, nos primeiros anos de sua instalação na América portuguesa, implica perceber a riqueza particular de cada um dos testemunhos que os jesuítas nos deixaram através de suas cartas, cuidadosamente compiladas pelo Pe. Serafim Leite'.

1. A empresa do Pe. Serafim Leite concretizou-se em cinco volumes da coleção Monumenta Historica Societatis lesu (respectivamente, vols. $79,80,81,87$ e 99), que compõem os cinco primeiros volumes da (sub-)coleção Monumenta 
Embora nos primeiros momentos de vida da Ordem de Santo Inácio o objetivo e a importância da correspondência estivessem claramente definidos, várias foram as mudanças instituídas na política de comunicação da Companhia ao longo do anos 2 .

Deste modo, se $\mathrm{em}$ relação à correspondência a Companhia procurava adaptar-se à realidade do mundo que buscava transformar, Ad maiorem Dei gloriam, o seu governo também oscilava, recuando e avançando, amoldando-se, com primor, ao que era secular, temporal, humano ${ }^{3}$.

Ao chegar ao Novo Mundo, nove anos após a sua fundaçāo, a Companhia de Jesus revelou com mais clareza essas vacilações. Isolado do centro de decisōes por distâncias então consideráveis e imerso cm um império que procurava se organizar com a instalação do Governo-geral, o governo jesuítico da América portuguesa mostrou-se hesitante $e$, conseqüentemente, inovador, como explica José Carlos Scbe Bom Mcihy: "Como condição de sobrevivência, [a Companhia de Jesus] adaptou-se à terra, descobriu suas próprias soluções, buscando o prático da cultura selvagem" (MEIHY, 1975, p. 69)4.

Brasiliae. Os primeiros três foram editados pela Comissão do IV Centenário da Cidade de Säo Paulo, em 1954. O último, Complementa Azevediana, constitui um trabalho exclusivo sobre o Pe. Inácio de Azevedo (1526-1570), primeiro Visitador da Província do Brasil e designado Provincial do Brasil, cargo que nāo chegou a ocupar, pois faleceu nas māos de calvinistas franceses a caminho do Novo Mundo.

2. Estas alteraçōes, aliás, seguiram muitas vezes o próprio percurso de transformações políticas no interior da Ordem, como aconteccu, por exemplo, por ocasião da clcição do Pe. Francisco de Borja para Prepósito Geral, em 1565.

3. Essa "mobilidade" inicial, inclusive, parece ter sido deixada em segundo plano, principalmente por análises que têm privilegiado um exame da Ordem que poderiamos chamar de "retrospectivo", esquecendo-se que a Companhia da segunda metade do sćculo XVI era difcrente do que veio a ser, principalmente, no século XVIII. A respeito da lenta e conturbada gênese da Companhia de Jesus vale conferir a obra do Pe. André Ravier, SJ (principalmentc: Ravier, 1974, pp. 127-228).

4. Comentava o Pe. Nobrega, primeiro Superior e primeiro Provincial da Companhia no Brasil, em uma carta
Sob o comando do Pe. Manuel da Nóbrega, os jesuítas rapidamente se alastraram por todo o território colonial $^{5}$, zelando pela religiosidade católica no interior das comunidades coloniais portuguesas e promovendo a difícil tarefa de evangelização dos indígenas ${ }^{6}$.

Neste labor apostólico, não foram poucas as dificuldades que encontraram. Desde cedo, depararam-se com uma sociedade portuguesa colonial que consideravam desregrada, inundada por vícios e descontroles. Do lado dos indígenas, os Padres, incapazes de perceber a singularidade da cultura ameríndia, defrontaramse com a diferença radical de costumes e práticas, que logo procuraram extirpar para, em seu lugar, instaurar as suas concepções de pecado, de verdade, de amor $\mathrm{e}$ de fé. Por outro lado, a própria Companhia de Jesus, em gestaçāo, "jovem e ainda cá́lica" (RAVIER, 1974, p. 416), buscava ordenar-se e regrar seu funcionamento e estrutura interna?.

cndereçada ao scgundo Prepósito Geral. Pe. Dicgo Laynes (1512-i565), em 1561: "O modo de proceder no tempo que eu fui Provincial nesta Província do Brasil, variou de muitas maneiras quanto ao seu governo, porque eu seguia urn caminho $\mathrm{c}$ depois, por carta c avisos que tive de Portugal, e muito mais depois da vinda do Pe. Luís da Grã [cm 1553], por seu consetho caminhava por outro $\mathrm{cm}$ algumas coisas e em outras duvidada e as comunicava a Portugal e dava a inforınação que havia e me respondiam tanto de Roma como de Portugal e aquele caminho seguia depois" (Leite, 1954c, p. 356).

5. Em 1549, inslalaram-se na Bahia e o Pe. Leonardo Nunes foi mandado para São Vicente. No ano seguinte, o Pe. Nóbrega percorria a capitania de Pernambuco. En I55I, o Pe. Afonso Braz e o lr. Simão Gonçalves se instalavam no Espirito Santo. Em 1552-1553, o Pe. Juan de Azpilcueta Navarro chegava à capitania de Porto Seguro. Na década de 1560, os jesuftas visitaram diversas povoaçőss ao sul de Săo Vicente (Jtanhaém, Iguape, Cananéia). Em 1563, asscntaram em São Jorge de lihéus (Pe. Diogo Jacome e Pe. Luiz Rodrigues). Em 1565, ocorreu a instalação definitiva no Rio de Janeiro.

6. Neste sentido, lembra Paulo de Assunção: "O papel do inaciano tendeu a ser um elo de ligaçāo e equilíbrio entre as partes componentes da sociedade e, por conseguinte, mantenedor e defensor da legitimidade dos governos nacionais nas terras americanas" (Assunçāo, 1995, p. 4).

7. A esse respeito, ver: Ravier, 1974, pp. 229-281. 
O plano jesuítico da conversão, deste modo, foi marcado pela idéia de ordem: cra necessário ordenar, regrar e hierarquizar a nova sociedade que se instalava no Novo Mundo, à imagem da sociedade mãe a portuguesa. $E$ as idéias de ordem e hierarquia $(i-$ nham raizes profundas na própria origem da Companhia de Jesus.

Marcada pelos Exercícios Espirituais de seu fundador, Inácio de Loyola (1491-1556), a Companhia de Jesus voltara-se para a formação de um homem de ação. Através dos Exercícios, o cristão devia confrontar-se com seu próprio interior, onde se debatiam o bem e o mal. Tratava-se, através de ưma técnica metódica e regrada, de assumir os pecados e redimirse, conformando-se à vontade de Deus. Ora, essa renovação espiritual interior revelava um homem profundamente apostólico, como lembra Henri DanielRops: "Desta forma, trabalhando unicamente em reformar o homem interior, Santo Inácio termina por construir um tipo de homem de ação, no qual a eficácia procederá diretamente do esforço empreen đido no plano da consciência" (DANIEL-ROPS, 1957, p. 50).

A vontade orientada $\mathrm{cm}$ direção a Deus, deste modo, adquiria um tom marcadamente conquistador. Era o mundo irremediavelmentc perdido que o jesuíta devia transformar como imagem de sua propria autodisciplina, construída metódica e racionalmente através da experiência dos Exercícios. A conversão ascética do cristāo renovado pelos Exercícios revelava-se ordenada, racional, tal qual a sua ação no mundo dos homens 8 .

Deste modo, a Companhia confomou a sua vocação essencialmente missionária. A sua própria estrutura interna era marcada, entāo, pela hierarquia e pela obediência, consagradas nas diversas partes de

8. Sobre as particularidades do ascetismo religioso, ver: Weber, 1982, pp. 309-410 e Weber, 1992, pp. 328-492. suas Constituições ${ }^{9}$. A sua vocação consistia na conquista espiritual do mundo.

Ao implantarem seu projeto de catequese no Novo Mundo, nas primeiras décadas da segunda metade do século XVI, no entanto, os jesuítas revclaram diversas concepções, ou melhor, concep̧̧ōes matizadas de como ele devia operar. A riqueza dos testemunhos jesuíticos, conservados através de suas cartas, revela, na verdade, a riqueza e diversidade de dois mundos em transformação: o Velho, sacudido pelas incertezas e conflitos religiosos, pela novidade das descobertas, pelas transformações no âmbito do saber; e o Novo, que assistia ao encontro de duas culturas diferentes, ao processo de instalaçāo de uma sociedade propriamente colonial, à imposição de novos e à transformaçāo de velhos valores societários e culturais.

Nesse conjunto de processos, os membros da Companhia de Jesus procuraram transformar a realidade do Novo Mundo à imagem de suas concepçōes rcligiosas: o plano da conversão, de fato, era único, mas as leituras da realidade colonial resultaram variadas, indicando, como lembrou Luís Filipe Barreto, a "pluralidade interna que acompanha a unidade do olhar missionário do Brasil e do Índio" (BARRETO, 1993, p. 608).

\section{O plano de Manuel da Nóbrega}

O Pe. Manuel da Nobrega revelou uma percepção singular nāo só da evangelizaçāo como também, do amplo processo de colonização do Brasil. Talvez pela sua própria posiçăo na hierarquia do governo

9. Embora as Constituiçōes só tenharn sido aprovadas pela primeira Congregaçāo Geral, em 1558, os trabalhos de sua redaçāo datam de 1539, quando Santo Iń́cio contava, entảo, com a ajuda de Jean Codure. Com a morte deste em 154l, Inácio continuou o trabalho até 1547, momento em que passou a ser auxiliado pelo recém-nomeado Secretário da Companhia, Juan Altonso Polanco. 
jesuítico, já que foi Superior e Provincial durante os primeiros dez anos de instalação da Ordem na América portuguesa, seus relatos ultrapassem o mero plano da conversão ${ }^{10}$. De fato, as suas cartas revelam uma preocupação com os rumos do que viria a ser a sociedade portuguesa nos trópicos - neste sentido, não era fortuita a sua chegada junto com o primeiro Governador-geral do Brasil, Tomé de Sousa (15031579).

Já $\mathrm{cm}$ suas primeiras cartas, dirigidas ao Provincial de Portugal, Pe. Simão Rodrigues (1510-1579), explicitava as linhas gerais de seu plano evangelizador. Apontava a importância da figura do Governador para a evangclização (cf. LEITE, 1954a, p. 115). Acenava para a necessidade de um Vigário Geral, "para que ele com temor c nós com amor procedendo, se busque a glória do Senhor" (LEITE, 1954a, p. 118). Indicava a urgência de se enviarem do Reino moças para casarem com os cristãos que, em sua grande maioria, estavam amancebados com suas cscravas (cf. LEITE, 1954a, p. 120). Finalmente, recomendava uma solução urgente para o problema dos salteamentos dos indígenas, o que se faria mediante a autoridade do Governador, pois pedia an monarca, por intermédio do Pe. Rodrigues, "[...] que S.A. encomendasse isto muito ao Governador, digo que mandasse provisāo para que entregasse todos os cscravos salteados para os tornarmos a sua terra, e que por parte da justiça se saiba c se tire a limpo" (LEITE, 1954a, p. 123).

Como se pode perceber, para o Pe. Nóbrega eram essenciais o avigoramento das autoridades civil e

10. De 1549 a 1553 Nóbrega foi o Superior da Companhia no Brasil (a colónia ainda estava vinculada a Província de Portugal). Em abril de 1553, foram concedidos a Nóbrega poderes de Vice-provincial: em julho do mestmo ano o Brasil foi elevado a Província e Nóbrega nomeado Provincial, cargo que manteve até 1560 e ao qual foi reconduzido no ano de sua morte, 1570. Lembre-se, ainda, que, em 1558, foi criada a Assistência de Portugal, unidade que congregava várias Províncias e à qual se vinculou a do Brasil. eclesiástica, assim como a correta aplicação do que ele denominava justiça e, igualmente, a conformação da população das comunidades portuguesas aos ditames da Igreja e do direito. Cabia, portanto, ordenar a sociedade que se construía na América portuguesa.

\section{A marca da desordem}

Para Luiz Koshiba, ao longo da colonizaçāo diversos projctos de dominação e povoamento foram se definindo. Estas iniciativas manifestavam as próprias contradições da sociedade portuguesa, onde se opunham um estamento aristocrático-clerical e as camadas burguesas. Neste sentido, a Coroa, com o auxílio inestimável dos jesuítas, procurou traçar um plano de dominaçāo global da colônia, mantendo índios e colonos sob o seu controle.

Estes, por sua vez, insurgiam-se contra a sociedade estamental "estruturada com base em privilégios juridicamente consagrados" (KOSHIBA, 1988, p. 154). A luxúria possível no Novo Mundo e o primado do lucro confrontavam constantemente os povoadores portugueses contra Padres e autoridades, fićis defensores da autoridade tradicional.

Deste modo, subtraindo-se à lógica da dominação imperial e à autoridade político-religiosa, os colonos instauravam a desordem no cenário colonial. Não sem razāo, escrevia Nóbrega ao Cardeal Infante D. Henrique, em 1560:

E certifico a V.A. que nesta terra, mais que em nenhuma outra, não poderá um Governador e um Bispo, e outras pessoas públicas contentar a Deus Nosso Senhor e aos homens, c o mais certo sinal de nảo contentar a Deus, é contentar a todos, por estar o mal mui introduzido na terra por costume (LEITE, 1954c, p. 240)"'.

11. Em uma carta dirigida anos antes a Santo Inácio, o Pe. Nóbrega escrcvia: "[...] e a esta terra só têm vindo até agora desterrados, da mais vil e perversa gente do Reino" (Leite, 1954b, p. 17I). 
Păra Nóbrega, diversos eram os problemas causados pelos povoadores portugueses, pois não demonstravam nenhum interesse na cristianização dos indígenas, nem mesmo na sua própria ${ }^{12}$. A cles se juntava um clero secular essencialmente desregrado e dissoluto, que pouco zelava pelo viver da comunidade cristã: "Cá há clérigos, mas é a escoria que de lá vem [...]" (LEITE, 1954a, p. 116).

No âmbito dos recém-chegados à fé católica os problemas eram outros, porém não menores. A percepção da diversidade, como já foi assinalado, nāo levou à sua compreensão. Antes, o entendimento de alguns mecanismos de ordenação da sociedade indígena, como o papel dos pajés, dos "principais" e do sistema de parentesco das várias comunidades, serviu para aguçar as técnicas de conversão e conseqüente desestruturaçāo dessas sociedades ${ }^{13}$.

O problema com os indígenas residia basicamente na questão dos costumes. Se em um momento inicial a conversão parecia fácil, aos poucos, a prática da antropofagia, da poligamia, do nomadismo, da feitiçaria $\mathrm{e}$ as incessantes nudez e embriaguez erigiram uma fronteira intransponível entre jesuítas e índios.

12. A respeito de todos esses problemas, vale conferir uma longa carta que Nóbrega escreve a Touné de Sousa, em 1559, onde faz uma sinopse de todos os estorvos causados pelos cristãos ponugueses. Cf. Lcite, 1954c, pp. 76-80.

13. Como explica Adriana Romeiro: "Essa incapacidade de perceber a relatividade dos códigos, valores e princípios o pressuposto da noçâo de cultura - flagrante nos assuntos religiosos, $\hat{c}$ as vezes, superada, e os jesuítas vāo se dando conta de que certos aspectos do universo indígena têm sentido muito especifico, totalmente distinto de seu próprio universo. Desta percepção não decorreu obvjamente o respeito pela cultura indígena e pelo seu dircito à existência; ao contrário, ela propiciou o refinamento de uma estratégia de seduçāo, calcada na idéia de que 'a semclhança é causa de anor', isto é, fazer-se igual aos índios, adotando alguns de seus costumes, para atrailos à fé cristã" (Romeiro, 1991, p. 51).
Cruzar essa fronteira significava, para Nóbrega, aproximar os nativos do modo de vida cristāo, o que terminou se revelando possível apenas através da erradicação dos seus "abomináveis" costumes.

Esses hábitos, para os Padres, constituíam igualmente uma concepção desordenada da vida. De fato, como mostrou Luiz Felipe Baêta Neves, a poligamia, a antropofagia e a nudez, por exemplo, revelavam-se formas não ordenadas de uso do corpo (NÉVES, 1978. p. 56). A embriaguez, igualmente, descontrolava os indígenas afastando-os de qualquer possibilidade de comportamento regrado que os jesuítas procuravam thes ensinar ${ }^{14}$.

Entretanto, não era só nos costumes que o Pe. Nóbrega notava o desconcerto das comunidades indígenas. A ausência de uma autoridade centralizada e as guerras inter-tribais realizadas por "ódio" representavam uma inversāo perigosa para o primeiro Provincial.

Frente a todos esses problemas, o Pe. Nóbrega foi construindo, ao longo dos anos, um plano geral de evangelização e colonização, que envolvia, além da conversão dos indígenas, a constituição e formação de uma comunidade colonial onde os nativos e os diversos membros da sociedade ocidental povoadores, padres, autoridades - tivessem seu papel e lugar cuidadosamente definidos ${ }^{15}$.

Como se ressaltou acima, as concepções de Nóbrega manifestam diversos elementos comuns do

14. O entāo Irmão e depois Padre José de Anchieta (1537. 97), nos primeiros anos de sua estadia na América portuguesa, recupera em várias de suas cartas o problema do descontrole causado pela embriaguez, como nesta carta escrita a Santo Inácio: "Este e o seu maior mal, donde lhes vêm todos os outros. De fato, quando cstão mais bêbados, renova-se a memória dos males passados comefando a vangloriar-se deles logo ardem no desejo de matar inimigos e na fome de carne humana" (Leite, 1954b, p. 176).

15. Sobre o lugar dos próprios jesuítas, Nóbrega não tinha dúvidas: "[...] pessoas públicas, como somos os da Companhia [...]" (Leite. 1954a, p. 371). 
que se poderia chamar "pregação inaciana", presente nas cartas dos demais jesuítas e na própria estrutura e "espírito" da Companhia de Jesus". Não obstante, o estudo de sua correspondência revela lugares particulares, próprios de seu pensamento acerca da colonização.

\section{A marca da ordem}

Em uma longa carta escrita ao primeiro Governador-geral do Brasil, Tomé de Sousa, em 1559, Nóbrega dava conta das suas principais preocupaçōes no labor apostólico do Novo Mundo:

Desde que nesta terra estou, que vim com V.M., dois desejos me atormentaram sempre: um, de ver os cristãos destas partes reformados em bons costumes, e que fossem boa semente transplantada nestas partes que desse cheiro de bom exemplo; e outro, ver disposiçāo no gentio pera se the poder pregar a palavra divina, e eles fazerem-sc capazes da graça e entrarem na Igreja de Deus, pois Cristo $\mathrm{N}$. Senhor por eles também padeccu (LEITE, 1954c, p. 71).

Ao tentar implementar seus objetivos, como Provincial da Companhia de Jesus e, depois, como pessoa influente nos destinos da Ordem no Brasil ${ }^{17}$, o Padre procurou desenvolver um plano que melhor permitisse a consecução de suas intençōes. $E$ foi nas idéias de revigoramento da autoridade constituída $\mathbf{c}$ de sujeição dos nativos que encontrou os meios mais

16. Luiz Felipe Baêta Ncves se vale do conceito de "ideologia religiosa cristã" como uma categoria explicativa para compreender $\mathrm{c}$ analisar as manifestaçōes e estrutura da catequese no Brasil. Cf. Neves, 1978, pp. 44-97.

17. Em 1561, Nobrega, nāo mais Provincial, escrevia no segundo Geral da Companhia. Pc. Diego Laynes: "Pareceu-me a mim também que V.P. desejaria ter também de mim informação como de pessoa pela qual todas passaram pela mão e a mais tempo que com elas trato, tanto no entendimento como na execução delas, e assim nesta darei conta do que se duvida, embora sejam coisas antigas e que já se têm escrito, para que não faltando informações de todas as partes, possa escoIher e prover como in Domino the parecer" (Leite, 1954c, pp. 256-257). eficazes para efetivar a sua política, como destacava na continuação da carta a Tomé de Sousa:

Destes dois desejos que digo, me nasciam outros, que era desejar os meios para que isto tivesse efeito, e destes escolhia dois que me pareciam melhores: um, era desejar Bispo, tal qual V.M. e eu o pintavamos cá pera reformar os cristãos, e outro era ver o gentio sujeito c metido no jugo da obediência dos cristāos [...] (LEITE, 1954c, p. 72) ${ }^{18}$.

A desordem instaurada nas comunidades portuguesas coloniais implicava não somente a subtração à autoridade político-religiosa tradicional - como fica claro a partir da carta endereçada ao Infante $D$. Henrique, citada atrás, mas, igualmente, à supressāo de uma ordem jurídica específica.

E era justamente pelo reforço dessa autoridade e dessa ordem jurídica que Nóbrega percebia a instalação de uma socicdade ordenada. Nesse sentido, os jesuítas se recusavam a admitir os colonos salteadores $\mathrm{c}$ amancebados à confissão e admocstavam os blasfemadores públicos, "lendo-lhes as penas do direito" (LEITE, 1954a, p. 121). Do mesmo modo, discutiam-sc no interior da Companhia de Jesus a legalidade, os limites e os modos de escravização dos indígenas.

Assim, determinar normativamente todas estas questões, implicava impor uma conduta legal ao conjunto da colônia. Como lembra Wilson Martins: "Nóbrega, desde sua chegada, em 1549, defrontouse com situações de fato que era imprescindível transformar em situações jurídicas" (MARTINS, 1978, p. 45).

Através dessa conduta normativa, buscava-se o domínio de uma realidade do processo de colonização ${ }^{19}$. Era por essa razão que Nóbrega lamentava o

18. Bon parte da literatura tem ressaltado essa característica racional do projeto jesuítico.

19. Como destaca Eugene Genovese, embora analisando a sociedade escravista do sul do Estados Unidos, no século XIX: 
funcionamento falho da justiça leiga colonial. A falta de controle e punição dos salteamentos $\mathrm{e}$ de outras violências praticadas pelos colonos contra os índios impedia, então, qualquer possibilidade de instalação de uma sociedade ordenada na América portuguesa. A vinda de colonos comprometidos com o proveito público e geral do Rcino e da Igreja era, assim, um elemento essencial para a consecuçāo de seu plano evangclizador. Deste modo, escrevia a Santo Inácio, em 1555:

Torno a dizer a V.P. que se esta costa do Brasil não se povoar de melhor gente do que a que até agora tem vindo a cla, a qual faça viver os índios em razāo e justiça, nāo se pode fazer mais conta dela, que de sustentar-se alguns Irmāos da Companhia em colégios, c ganhar-se alguns filhos dos Índios (LEITE, 1954b, p. 17i) ${ }^{20}$.

A mesma situação era detectada no âmbito clerical, como vimos. A solução, para Nóbrega, foi, desde o início, o reforço da autoridade eclesiástica: "Dos sacerdotes ouço coisas feias. Parece-me que devia V.R. [Pe. Simão Rodrigues] lembrar a S.A. [D. João

"[...] o poder do Estado, cuja conquista constitui o objeto de toda luta política, representa uma tentativa de monopolizar e, desta forma, disciplinar e legitimar as armas da violência. Uma das funçōes primárias do direito refere-se aos meios com os quais o uso das armas se torna cticamente sancionado. [...] A idéia de 'hegemonia' que, depois de Gramsci, tornou-se central no marxismo ocidental, implica antagonismos de classe; mas também implica, em uma deterıninada época histórica, a habilidade de uma classe particular $\mathrm{cm}$ conter esses antagonismos num terreno em que sua legilimidade não $\mathcal{C}$ seriamente questionada" (Genovese, 1976, pp. 25-26).

20. Dois anos mais tarde escrevia ao terceiro Provincial de Portugal, Pe. Miguel de Torres (1507-1593): "Deste modo nenhuma ajuda nem favor temos nisto dos cristāos, mas antes muitos estorvos, tanto de suns palavras como do exemplo de suas vidas, dos quais muito lhes ensinam [aos nativos] senīo a furtar $c$ adulterar e fornicar com as infiéis c outros males de que o gentio se escandaliza" (Leitc, 1954b. p. 400).

21. Em sua primeira carta, surpreso com a nudez dos índios, logo aponta a solução: “Todos estes que tratam conosco dizem que querem ser como nós, senīo que nảo têm com que se cubram como nós, e este só inconveniente têm. [...] Pare-
III] um vigário geral, porque sei que mais moverá o temor da justiça que o amor do Senhor" (LEITE, 1954a, p. 114).

O plano ordenador verificou-se igualmente $\mathrm{cm}$ relação à evangelização dos nativos. Já em sua terceira carta, enviada ao Provincial de Portugal, Nóbrega deixava claras suas preocupações: "[...] e assim também que as leis positivas não obriguem ainda este gentio, até que vão aprendendo de nós por tempo, scilicet, jejuar, confessar cada ano e outras coisas semelhantes" (LEITE, 1954a, p. 124).

A questão dos costumes indígenas, como dissemos, revelou-se um dos problemas centrais do plano de conversão pensado por Nóbrega. A solução aventada era a sua erradicação, tarefa que desde cedo o primeiro Provincial procurou implementar ${ }^{21}$. Neste sentido, o plano de Nóbrega assentava na idéia de que havia que aproximar os índios do modo de vida cristão. Para efetivar este plano, os jesuítas valeramse dos meios mais diversos possíveis, como o próprio Nóbrega relata ao Pe. Simão Rodrigues, em 1552:

Se nos abraçarmos com alguns costumes deste gentio, os quais não sāo contra nossa fé católica, nem sāo ritos dedicados a ídolos, como é cantar cantigas de Nosso Senhor $\mathrm{cm}$ sua língua pelo seu tom $\mathrm{c}$ tanger seus instrumentos de música que eles usam em suas festas quando matam contrários e quando andam bêbados, e isto para os atrair e deixarem os outros costumes essenciais e, permitindo-lhes e aprovando-lhes estes, trabalhar por the tirar os outros [...]

ce-me que não podemos deixar de dar roupa a estes que querem ser cristâos, repartindo-a até ficarmos todos iguais com eles, ao menos por nāo escandalizar aos meus irmanos de Coimbra, se souberem que por falta de algumas ccroulas deixa urna alma de ser cristã e conhecer a seu Criador" (Leite, 1954a, pp. 111-113). Como explica Mary del Priore, no Renascimento, “[...] a roupa, nāo contente de distingüir o homem do animal, toma-se também um costume fundamental de discriminação social e cultural” (Priore, 1995, pp. 50-51). 
Porque a semelhança é causa de amor (LEITE. 1954a, pp. 407-408).

A idéia de que "a semelhança é causa de amor" indicava, por um lado, que os jesuítas deviam tornarse semelhantes aos indigenas para melhor convertê$\operatorname{los}^{22}$. Mas, mais ainda, ilustrava a noção de que os indígenas deviam se tornar iguais aos europeus; essa semelhança era causa de amor, pois era a obra de conversão. Deste modo, o que tornava os índios diferentes eram os seus costumes $\mathrm{e}$ modo de vida. Não era por acaso que N6brega, ao saber, por ouvir dizer, que diversas tribos indígenas se aproximavam da forma de vida cristã argumentava:

E tenho sabido de um homern gentio que está nesta terra, que [os Carijós] vivem em obediência de quem os rege, e não comem came humana. Andam vestidos de peles. O qual tudo é disposição para mais facilmente se converter e sustentar (LEITE, 1954a, p. 268).

Ora, com o passar do tempo, Nóbrega foi percebendo a dificuldade de ver efetivada uma real transformação no modo de vida do indígenas. Esse processo foi acompanhado de uma singular transformação de seu discurso catequético. De fato, aos poucos sua correspondência revela um plano catequético centrado na "sujeiçāo" dos indígenas como única possibilidade de se ver concretizada a sua conversão $\mathrm{c}$ conseqüente inserção no seio da sociedade colonial ${ }^{23}$.

E a "sujeição" permitia justamente, para Nóbrega, uma efetiva transformação em igual daquilo que era

22. O mesmo mecanismo foi detectado por Luís Filipe Barreto em relação à Carta de Pero Vaz de Caminha: "A estratégica comunicação pauta-se por uma procura de lugares de contacto passiveis de futura redução/transformação do Outro ao Mesmo" (Barreto, 1983, p. 179).

23. Apostou-se, tambem, como mostrou Mary del Priore, na evangelização das crianças indígenas, verdadeiro "papel em branco" (Priore, 1991). Este tema, aliás, gerou alguns problemas com a cúpula da Companhia, a quem não parecia conveniente a aceitação do encargo de meninos. diferente. "Igualar" os índios significava, deste modo, aproximar os nativos ao modo de vida cristão e, conjuntamente, anular as diversas características que diferenciavam e opunham os vários grupos indígenas. Tratava-se então de introjetar-Ihes uma ordem social e religiosa que deveriam ser capazes de reproduzir.

Foi com os "aldeamentos", principalmente a partir do governo de Mem de Sá (?-1572), que Nóbrega cncontrou a concretização de seu plano de evangelização. Embora presente no Regimento de Tomé de Sousa ${ }^{24}$, a idéia de fundar aldeias com índios de várias procedências deveu-se, precipuamente, ao empenho do Pe. Nóbrega; foi uma resposta jesuítica aos problemas suscitados pela catequese ao longo dos vários anos de experiência apostólica no Novo Mundo.

Nos aldeamentos se introduziu um série de proibições e permissões, de regulamentos e correições, a cargo dos padres e das autoridades civis, montandose uma completa regulamentação jurídica da vida dos indios, em que se misturava a organização religiosa com a ordem do trabalho ${ }^{2 s}$.

Neles se fazia cada vez mais presente a autoridade do Governador, castigando-se qualquer insubordinação. Deste modo, enfim, Nóbrega via a possibilidade de o seu plano se concretizar:

O ano passado de 1559 me deram uma de Vossa Alteza [D. Henrique] em que me manda que the escreva e avise das coisas desta terra que ele deve saber. E pois assim

24. "Item. Porque parece ser grande inconveniente os gentios que se tornarem crisıăos morarem na povoaçăo dos outros e andarem misturados com eles e sera mujto serviço de Deus e meu apartarem-nos de sua conversaçāo vos encomendo e mando que trabalheis muito por dar ordem como os que forem cristāos morem juntos perto das povoaçöes das ditos capitanias para que conversem com os cristăos e nāo com os gentios e possam ser doutrinados e ensinados nas coisas de nossa sanla fe" ("Regimento que levou Tome de Sousa Governador do Brasil", 1950, pp. 67-68).

25. A respeito dos aldeamentos, ver: Leite, 1939, pp. 42. 60 e Leite, 1940, pp. 51-52. 
mo manda the darei conta do que V.A. mais folgará de saber que é da conversão do gentio, a qual, depois da vinda deste Governador Mem de Sá cresceu tanto que, por falta de operários muitos, deixamos de fazer muito fruto. E todavia com esses poucos que somos se fizeram quatro igrejas em povoações grandes [Espírito Santo, São Paulo, São Joāo e Santiago, todas na Bahia], onde se ajuntou muito número de gentio pela boa ordern que a isso deu Mem de Sá com os quais se faz muito fruto, pela sujeiçāo e obediência que têm ao Governador; e enquanto durar o zelo dele se irão ganhando muito, mas, cessando, em breve sc acabará tudo, ao menos entretanto os que não têm ainda lançadas boas raizes na fé e bons costumes (LEITE, 1954c, pp. 238-239),

\section{Sobre a natureza dos nativos}

Como se pode perceber, para Nóbrega, a evangelizaçāo era possível, desde que se recorresse à sujeição dos nativos, única forma de ordenar-lhes a vida, conseqüentemente, de impor-lhes um modo de vida cristão e também de inseri-los na sociedade que se construía no Novo Mundo.

Ora, esse plano evangelizador, descrito c repensado pelo jesuíta ao longo de sua experiência catequética, fundamentava-se em uma concepção singular a respeito da natureza dos indígenas. E é principalmente em um texto "literário" escrito nos anos 1556 e 1557, o "Diálogo Sobre a Conversão do Gentio", que o Padre vai explicitar as suas idéias.

O texto se constrói através um diálogo entre os Irmãos Mateus Nogueira e Gonçalo Alvarez ${ }^{26}$. A idéia básica do "Diálogo" é a de que a bruteza dos indígenas, manifestada nos seus costumes. e organi-

26. "Porque me dá o tempo c lugar para me alargar, quero falar com uneus Irmãos o que meu espírito sente, c tomarei por interlocutores ao meu trmão Gonçalo Alvarez, a quem Deus deu graça para ser trombeta de sua palavra na Capitania do Espírito Santo, e com meu Irmảo Mateus Nogueira, ferreiro de Jesus Cristo, o qual, posto que com palavra não prega, fálo com obras e marteladas" (Leite, 1954b, p. 319). zação social, e que tanto dificultava o trabalho dos Padres, não advinha de uma bestialidade irremediável (indios animais) ou mesmo de uma presumida filiação demonol6gica (índios demônios) ${ }^{27}$. Antes, a brutalidade, comum a todos os povos, originara-se com o pecado original ${ }^{28}$. Entretanto, ao contrário de outras naçōes, os nativos do Novo Mundo, por ocasião de uma maldição ocorrida após o Dilúvio, nāo haviam tido "criaçăo" nem "polícia"29". Neste sentido, comentava Nóbrega ao Pe. Simāo Rodrigues, em 1552: “[...] e, por outra parte, eu nấo sei quando tanto gentio se poderá vestir, pois tantos mil anos andou sempre nu [...]" (LEITE, 1954a, p. 408).

Ora, a superaçāo da bestialidade dos índios, em direção à conversão, far-se-ia, justamente, através da criação, como comentava o Ir. Mateus Nogueira ao Ir. Gonçalo Alvarez:

Porém, por vos fazer a vontade, vos contarei que já vimos índios desta terra com mui claros sinais de terem a verdadeira fé no coração e mostraram-no por obra, não somente dos meninos que criamos conosco, mas também dos ouIros grandes de mui pouco tempo conversados (LEITE, 1954b, pp. 340-341).

Desse modo, através de uma perspectiva que buscava na história bíblica os seus fundamentos, viabilizava-se o plano evangelizador de Nóbrega. Como dissemos acima, a forma ideal dessa transfor-

27. Sobre a análise desta questāo nas divèrsas fontes coloniais, ver: Souza, 1989, pp. 49-72.

28. Esclarece o Ir. Mateus Nogueira: "Depois que nosso pai Adĩo pecou, como diz o psalmista, năo conhecendo a honra que tinha, foi tornado semelhante à besta, de maneira que todos, tanto Portugueses, como Castelhanos, como Tamoios, como Aimorés. ficamos semelhantes a bestas por natureza corrupta, e nisto somos todos iguais" (Leite, 1954b, p. 333).

29. Para Manuel Marzal, o Pe. Nóbrega. deste modo, “[...] adianta-se à clássica tese de Acosta [...] de que os índios podiam ser verdadeiros cristãos, e insiste, como Acosta, no caráter 'cultural' e não 'natural' das dificuldades" (Marzal, 1992, p. 56). Tambérn a respeito do tema dos diversos níveis culturais dos indígenas, ver: Lestringant, 1995. 
mação, elaborada pelo pensamento estratégico de Nóbrega foram os aldeamentos.

\section{Conclusões}

A análise do plano de evangelização pensado pelo $\mathrm{Pe}$. Manuel da Nóbrega e de algumas das concepções que o fundamentam indica que o exame do processo de conversāo pode ser orientado no sentido de se tentar entender quais foram as bases intelectuais que nortearam a ação dos padres jesuítas no Novo Mundo.

Assim, as noções de ordem e de hicrarquia, as concepções formuladas acerca da natureza dos índi-

\section{Bibliografia}

ASSUNÇĀO, Paulo de. "As metáforas religiosas na conquista da América portuguesa". Cadernos de História Social. n I, junho de 1995, pp. 3-19.

BARRETO, Luís Filipe. Descobrimentos e Renascimento: Formas de Ser e de Pensar nos Séculos XVI e XVI. Lisboo, Imprensa Nacional/Casa da Moeda, 1983.

"O Brasil e o Índio nos Textos dos Jesuítas do Século XVI" (resumo da conferência). In: Missionação Porruguesa $e$ Enconsro de Culturas II. Braga, 1993, pp. 607-608.

DANIEL-ROPS, Henri. Une ère de renouveau: la Réfurme catholique. Paris, Fayard; 1957.

DIAS, José Sebastião da Silva. Os Descobrimentos e a Proble. mática Cultural do Século XVI. Lisbon, Editorial Presença, 1982.

GENOVESE, Eugene. Roll. Jordan. Roll: the World the Slaves Made. New York, Pantheon, 1976.

KOSHIBA, Luiz. A Honra e a Cobiça: Estudo Sobre a Origem da Colonização. São Paulo. Tese de doutorado apresentada à Faculdade de Filosofia, Letras e Ciências Humanas da USP, 1988, 2 vols. os, dos rumos do plano evangelizador e colonizador inserem-se num quadro de transformaçōes em curso na Europa quinhentista, onde se formou a mentalidade dos Padres jesuítas.

Recuperar essa relação entre Velho e Novo Mundo significa tentar entender de que modo os jesuítas cntenderam e refletiram sobre o seu trabalho apostólico à luz de sua própria formaçāo cultural. Deste modo, parece-nos, torna-se possívcl não só estudar as "incidências da Expansão nos destinos culturais da Europa" (DIAS, 1982, p. 182), como fez José Sebastião da Silva Dias, mas, também, parafraseando o historiador português, as incidências da cultura européia nos destinos da expansão.

LEITE, Serafim, SJ. História da Companhia de Jesus no Brasil. Lisboa/Rio de Janeiro, Portugália/INL, 1939, vol. 11.

"A Expansão Portuguesa no Novo Mundo pela Acçāo Missionária (1492-1580)". In: BAlÃO, António, Cidade Herníni \& Múrias Manuel (orgs). História da Expansāos Purtuguessa no Mundo. Lisboa, Editorial Ática, 1940 , pp. 41-52, vol. III.

Cartas dos Primeiros Jesuriras do Brasil. São Paulo, Comissão do IV Centenário da Cidade de São Paulo, 1954a, vol. I.

Canas dos Primeirus Jesuínas do Brasil. São Paulo, Comissão do IV Centenário da Cidade de São Paulo, 1954b, vol. 11.

Cartas dos Primeiris Jesuítas do Brasil. São Paulo, Comissāo do IV Centenário da Cidade de São Paulo, 1954c, vol. III.

LESTRINGANT, Frank. "1492 e o Conhecimento". Cadernos de História Social, $n^{\circ} 2$, outubro de 1995, pp. 3-13.

MARTINS, Wilson. Hisiória da lnteligência Brasileira (15501794). Sảo Paulo, Cultrix, 1978, vol. 1. 
MARZAL, Manuel M. "Manuel da Nóbrega (1517-1570)". In: La Utopia Posible: Indios y Jesuitas en la América Colonial (1549-1767). Lima, Pontificia Universidad Católica del Perú, 1992, pp. 53-70.

MEIHY, José Carlos Sebe Bom. A Presença do Brasil na Companhia de Jesus: 1549-1649. São Paulo. Tese de doutorado apresentada à Faculdade de Filosofía, Letras e Ciências Humanas da USP, 1975.

NEVES, Luiz Felipe Baêta. O Combate dos Soldados de Cristo na Terra dos Papagaios. Rio de Janeiro. Forense Universitária, 1978.

PRIORE, Mary del. "Ó Papel Branco, a Infância c os Jesuítas na Colônia". In: (org). História da Criança no Brasil. São Paulo, Contexto, 1991, pp. 7-27.

"Selvagens na Igreja, a Frisa de Saint-Jacques de Dieppe: um Caso de Bricolagem Cultural". Revista de História, $\mathrm{n}^{\circ} 132,1^{\circ}$ semestre de 1995, pp. 43-58.
RAVIER, André, SJ. Ignace de Loyola fonde la Compagnie de Jésus. Paris, Desclée de Brouwer, 1974.

"REGIMENTO que leuou tome de Sousa Governador do Brasil (17. J2- 548)", transcrição paleográfica c notas por Alberto Iria. In: Anais do IV Congresso de História Nacional. Rio de Janeiro, Departamento de Imprensa Nacional, 1950, vol. Il. pp. 45-68.

ROMEIRO, Adriana. Todos os Caminhos Levam ao Céu: Relafóes entre Cultura Popular e Cultura Erudita no Brasil do Século XVI. Campinas, Dissertação de mestrado apresentada ao Instituto de Filosofia e Ciências Humanas da Unicamp, 1991.

SOUZA, Laura de Mello e. O Diabo e a Terra de Santa Cruz. São Paulo, Companhia das Letras, 1989.

WEBER, Max. Ensaios de Sociologia. Rio de Janeiro, Ed. Guanabara, 1982.

Economia y Sociedad. Buenos Aires, Fondo de Cultura Económica, 1992.

Endereço do autor: Rua Camargo Pimentel, 103 - CEP 13073-340 - Campinas - São Paulo - Brasil 